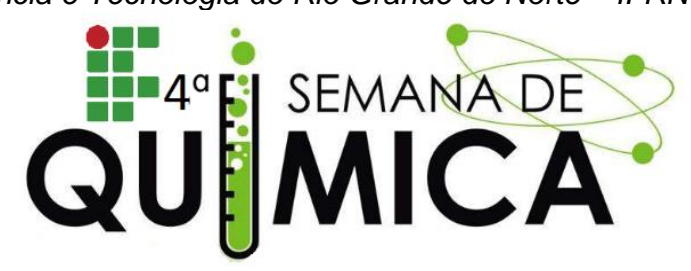

\title{
DESENVOLVIMENTO DE UM SABÃO COMERCIAL COMO PRÁTICA DO PROJETO INTEGRADOR DO CURSO TÉCNICO EM QUÍMICA
}

DOMINGOS, W. M. O. (IFRN - NC); PAIVA, R. K. A. (IFRN - NC); OLIVEIRA, J. R. S. (IFRN - NC); PORTUGAL, P. S. (IFRN - NC); SOUZA, J. A. C. (IFRN - NC); * OLIVEIRA, S. A. (IFRN - NC)

Palavras Chave: saponificação, sabão, projeto integrador.

\section{INTRODUÇÃO}

Este trabalho faz parte de um projeto integrador no IFRN de Nova Cruz no curso técnico Integrado de Química. E possui como objetivo o desenvolvimento de um sabão comercial. Trabalhado na busca da proporção ideal para a produção de sabão, controle de qualidade, estudo de viabilidade econômica, criação de uma marca e rotulagem do produto.

\section{METODOLOGIA}

Para a produção do sabão, foi utilizado óleo de soja comercial, $\mathrm{NaOH}$, álcool etílico e $\mathrm{H} 2 \mathrm{O}$. Foram realizadas duas baterias de testes de formulação do sabão variando a proporção dos reagentes, conforme Tabela 1 e Tabela 2.

Tabela 1 - Proporções da primeira bateria de testes

\begin{tabular}{|c|c|}
\hline $\mathbf{1 0}$ & $\begin{array}{c}100 \mathrm{~g} \text { de óleo, } 25 \mathrm{~g} \mathrm{NaOH}, \\
50 \mathrm{~mL} \text { de } \mathrm{H}_{2} \mathrm{O} \text { e } 25 \mathrm{~mL} \text { de álcool. }\end{array}$ \\
\hline $\mathbf{2 0}$ & $\begin{array}{c}100 \mathrm{~g} \text { de óleo, } 50 \mathrm{~g} \mathrm{NaOH}, \\
\mathrm{mL} \text { de } \mathrm{H}_{2} \mathrm{O} \text { e } 25 \mathrm{~mL} \text { de álcool. }\end{array}$ \\
\hline $\mathbf{3 0}$ & $\begin{array}{c}100 \mathrm{~g} \text { de óleo, } 25 \mathrm{~g} \mathrm{NaOH}, \\
100 \mathrm{~mL} \text { de } \mathrm{H}_{2} \mathrm{O} \text { e } 25 \mathrm{~mL} \mathrm{de} \mathrm{álcool.}\end{array}$ \\
\hline $\mathbf{4 0}$ & $\begin{array}{c}100 \mathrm{~g} \mathrm{de} \mathrm{óleo,} 25 \mathrm{~g} \mathrm{NaOH}, \\
\mathrm{mL} \text { de } \mathrm{H}_{2} \mathrm{O} \text { e } 50 \mathrm{~mL} \text { de álcool. }\end{array}$ \\
\hline
\end{tabular}

Tabela 2 - Proporções da segunda bateria de testes

\begin{tabular}{|c|c|}
\hline 1o & $\begin{array}{c}100 \mathrm{~g} \text { de óleo, } 13 \mathrm{~g} \text { de } \mathrm{NaOH} \\
\text { e } 13 \mathrm{~g} \text { de } \mathrm{H}_{2} \mathrm{O}\end{array}$ \\
\hline 2o & $\begin{array}{c}100 \mathrm{~g} \text { de óleo, } 13 \mathrm{~g} \text { de } \mathrm{NaOH} \\
\text { e } 8 \mathrm{~g} \text { de } \mathrm{H}_{2} \mathrm{O}\end{array}$ \\
\hline 3o & $\begin{array}{c}100 \mathrm{~g} \text { de óleo, } 13 \mathrm{~g} \text { de } \mathrm{NaOH} \\
\text { e } 4 \mathrm{~g} \text { de } \mathrm{H}_{2} \mathrm{O}\end{array}$ \\
\hline
\end{tabular}

\section{RESULTADOS E DISCUSSÕES}

No primeiro teste concentrações excessivas de $\mathrm{NaOH}$ e de álcool resultaram em sabões de baixa qualidade, ver Figura 1.

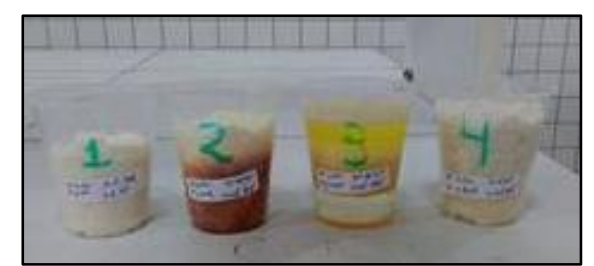

Figura 1 - Amostras da primeira bateria de testes

Na segunda bateria de testes retirou-se o álcool, e com isso resultou em um sabão mais macio que produzio uma espuma mais estável nos testes de lavagem, ver Figura 2

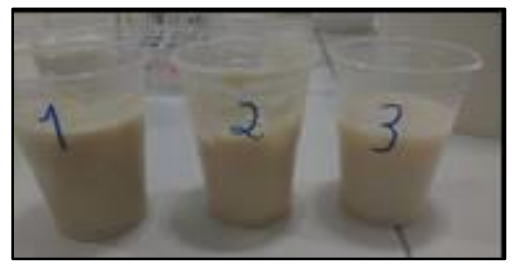

Figura 2-Amostras da segunda bateria de testes

\section{CONCLUSÃO}

Este trabalho ainda se encontra em andamento, onde as próximas etapas consistirão da escolha do corante e aroma para o produto, assim como as outras atividades necessárias para a criação de um produto comercial.

\section{REFERÊNCIAS}

BRASIL. ANVISA Agência Nacional de Vigilância Sanitária. Resolução Normativa $n^{\circ} 1 / 78$ de 27/11/78.

PERUZZO, F. M.; Química na abordagem do cotidiano 4a edição - são Paulo: Moderna, 2006. 